\title{
Chemotherapy-induced muscle wasting: an update
}

\author{
Dario Coletti
}

(1) Biology of Adaptation and Aging, Sorbonne Université, Paris, France; (2) Department of Anatomy, Histology, Forensic Medicine and Orthopedics, Sapienza University of Rome, Italy

This article is distributed under the terms of the Creative Commons Attribution Noncommercial License (CC BY-NC 4.0) which permits any noncommercial use, distribution, and reproduction in any medium, provided the original author(s) and source are credited.

\begin{abstract}
The majority of cancers are associated to cachexia, a severe form of weight loss mostly accounted for by skeletal muscle wasting. Cancer patients are often treated with chemotherapy, whose side effects are at times neglected or underestimated. Paradoxically, chemotherapy itself can induce muscle wasting with severe, cancer-independent effects on muscle homeostasis. Since muscle wasting is a primary marker of poor prognosis for cancer patients and negatively affects their quality of life, the systemic consequences of chemotherapy in this context must be fully characterized and taken into account. Ten years ago a precursor study in an animal cancer model was published in the European Journal of Translation Myology (back then, Basic and Applied Myology), highlighting that the side effects of chemotherapy include muscle wasting, possibly mediated by NF- $\kappa \mathrm{B}$ activation. This paper, entitled «Chemotherapy-induced muscle wasting: association with NF- $\kappa \mathrm{B}$ and cancer cachexia», is now being reprinted for the inaugural issue of the «Ejtm Seminal Paper Series». In this short review we discuss those results in the light of the most recent advances in the study of chemotherapy-induced muscle wasting.
\end{abstract}

Key Words: cancer cachexia, skeletal muscle atrophy, cisplatin, Folfiri, colon cancer C26 Eur J Transl Myol 28 (2): 153-157, 2018

Cancer-cachexia is a syndrome characterized by a severe decrease of body weight, accounted for by specific loss of skeletal muscle and adipose tissues. Cachexia, which is distinct from anorexia, is due to a combination of reduced food intake and metabolic changes, including high energy expenditure, excess catabolism and inflammation. ${ }^{1}$ The latter is linked to the production of cytokines by the tumor itself or the immune system of the host and plays a major role in the regulation of cancer cachexia. ${ }^{2}$ Pro-inflammatory cytokines, such as IL-6, act as double-edged swords since they recruit NK cells to attack the tumor cells, ${ }^{3}$ but also induce a systemic metabolic stress response that blocks the effects of anticancer immunotherapy. ${ }^{4}$ The pivotal role of fat tissue in driving the chronic inflammation that triggers cachexia was recently recognized. ${ }^{5,6}$ Skeletal muscle tissue is enriched in various stem cells but not in inflammatory cells in cachexia $;{ }^{7}$ nonetheless, it is a primary target of pro-inflammatory cytokines, which induce muscle fiber atrophy and stem cell dysregulation and apoptosis. ${ }^{8-10}$ Cachexia is associated to a large extent with cancers of the pancreas, oesophagus, stomach, lung, liver and bowel; this group of malignancies is responsible for $50 \%$ of all cancer deaths worldwide ${ }^{1}$ and cachexia is directly accountable for the death of about $20 \%$ of all cancer patients. ${ }^{11}$ Being associated with poor prognosis and a lower quality of life for patients, cachexia remains a major challenge in the management of cancer patients to date. Muscle wasting in cachexia affects both striated muscles, ${ }^{12,13}$ with important gender differences, likely linked to sex hormones. ${ }^{14}$ Great progress is being made in the understanding of the molecular mechanisms underlying muscle wasting, with a central role played by proteasome-mediated protein degradation. ${ }^{15}$ As a consequence, several treatments are now proposed to specifically counteract muscle wasting. ${ }^{16-18}$ Chemotherapy remains the elective treatment for different cancers since it directly induces the death of tumor cells and it helps endogenous host responses against cancer. ${ }^{19}$ However, loss of skeletal muscle during chemotherapy is prognostic of poor survival ${ }^{20}$. Consequently controlling muscle wasting especially in chemotherapy-treated patientsts is of the greatest importance. In spite of the significant effects of chemotherapy-induced muscle wasting, few studies have investigated this phenomenon up to date. When comparing the papers in PubMed containing the MeSH cachexia AND «muscle wasting» versus those containing the MeSH chemotherapy AND cachexia AND «muscle wasting» a striking difference appears: while the number 


\section{Chemotherapy and muscle wasting}

Eur J Transl Myol 28 (2): 153-157, 2018

of studies dealing with cachexia is increasing exponentially, the number of studies addressing chemotherapy effects in this context is far behind and adds up to a few per year. In this concise review the effects of chemotherapy on muscle wasting are discussed. One of the first papers describing chemotherapy-induced muscle wasting, by Damrauer et al., was first published in Basic and Applied Myology (BAM) ten years ago. ${ }^{21}$ On the ten anniversary of this publication, it is published again in this issue of European Journal of Translation Myology (EJTM), the rationale being that the results of that study are still valid and highly significant today; they will be discussed here along with more recent studies, which confirmed those findings and further characterized the underlying molecular mechanisms of chemotherapy-induced muscle wasting.

\section{Primordial studies on chematherapy-induced muscle wasting}

In the paper entitled «Chemotherapy-induced muscle wasting: association with $\mathrm{NF}-\mathrm{\kappa B}$ and cancer cachexia» the group headed by Denis Guttridge, at the Ohio State University, studied the effects of cisplatin, a common anti-cancer therapeutic agent, in a cancer cachexia animal model. The latter consisted in mice bearing a subcutaneously grafted colon carcinoma, the C26 tumor. ${ }^{21}$ Guttridge and co-workers found that «although cisplatin is able to reduce tumor burden as expected, muscle wasting in mice nevertheless persists. Strikingly, cisplatin alone was seen to regulate muscle atrophy, which was independent of the commonly implicated ubiquitin proteasome system» (Damrauer et al.). ${ }^{21}$ It is worth noting that then another group had reported opposite findings, i.e. that chemotherapy inhibits protein breakdown and promotes protein synthesis ${ }^{24,25}$, however, both studies showed that cisplatin induced body weight loss and muscle wasting in healthy mice, suggesting that chemotherapy does indeed induce muscle loss. Very likely, cisplatin triggers multiple responses in muscle tissue, which ultimately lead to muscle fiber atrophy while the role of protein ubiquitination and proteasomemediated degradation remains controversial (see also below). Clearly these studies were relevant in addressing cancer cachexia in the presence of chemotherapy, which contributes to mimicking clinical settings better.

\section{Mechanisms underlying chemiotherapy-induced muscle wasting}

As mentioned above, Guttridge's laboratory did not suggest a role for proteasome-mediated protein degradation during chemotherapy, while Attaix's group found that chemotherapy reduced proteasome-dependent protein degradation, both in the absence or presence of a tumor (see Damrauer et al., this issue). ${ }^{21}$ A possible explanation is that the first group did not directly measure proteasome activity, but rather Murf1 expression. Murf1 is a muscle specific ubiquitin ligase which leads proteins to the proteasome, but it is not unique in its role and it could be redundant with other ubiquitin-ligases, such as Atrogin1. In addition Murf1 provides an indirect estimate of protein degradation.

Interestingly, although, cisplatin induces Nf-KB expression, the latter is increased in muscle in the presence of a tumor and NF-kB activity is sufficient to trigger muscle wasting. Taken together these findings provide a possible mechanism whereby chemotherapy induces muscle wasting. ${ }^{26}$ In addition, the fact that NF$\mathrm{kB}$ targets not only muscle fibers but also muscle stem cells, ${ }^{27}$ suggests that chemotherapy may reach multiple targets, in addition to muscle fiber protein metabolism. The intriguing findings that NF-kB is involved in both tumor- and chemotherapy-induced muscle wasting suggested that common pathways are activated. This has been recently confirmed by the group of Andrea Bonetto, at Indiana University. ${ }^{28}$ By using a comprehensive approach based on liquid chromatography followed by mass spectrometry they compared the skeletal muscle proteome in C26-tumor bearing and chemotherapy treated mice (chemotherapy consisting of 5-fluorouracil (5-FU), Leucovorin (LV) and CPT-11, a combination also known as Folfiri). Authors found that cancer and chemotherapy promote the down-regulation of 235 and 345 muscle proteins, respectively, the vast majority of which were modulated in common. ${ }^{28}$ Mitochondrial dysfunction, TCA cycle, fatty acid metabolism, and Ca2+ signaling were among the altered pathways detected. ${ }^{28}$ Further insights about muscle mitochondria dysregulation following chemotherapy came from the same group which proved that mitochondrial depletion is MAPK-dependent. ${ }^{29}$ This is consistent with previous findings that muscle wasting is associated with upregulation of ERK1/2 and p38 MAPKs. ${ }^{30}$ Taken together these studies provide a rationale for using treatments to both counteract tumor growth and to reduce the side effects of chemotherapy.

\section{Countermeasures: would exercise be effective against chemotherapy side effects?}

In an elegant, recent study Bonetto and co-workers proposed the inhibition of the activin receptor $2 \mathrm{~B}$ (ACVR2B) signaling to counteract both cancer- and chemotherapy-induced muscle wasting, by using ACVR2B/Fc, a soluble ACVR2B fusion protein and inhibitor of receptor downstream signaling. ${ }^{31}$ ACVR2B/Fc was effective not only in counteracting Folfiri-induced skeletal muscle loss, but also the Folfiri negative effects on bone mass. ${ }^{31}$ Beside pharmacological treatments, many studies including ours have established that exercise counteracts cachexia and sarcopenia. ${ }^{32-35}$ The mechanisms underlying the beneficial effects of exercise against cachexia include autophagic flux regulation, ${ }^{36}$ the reduction of Pax7 expression in satellite cells, ${ }^{37}$ and the release of Hsp60 from muscle cells. ${ }^{38}$ This topic was recently reviewed, ${ }^{39-41}$ and it will be not further discussed here. 
Given that cancer and chemotherapy activate common pathways in muscle and exercise has proven effective against cancer-induced muscle wasting, several research groups have been prompted to study whether physical activity could have beneficial effects in the presence of chemotherapy as well. Indeed, several epidemiological studies and clinical trials indeed suggest that both resistance and endurance exercise should be an integral part of supportive care for cancer patients undergoing chemotherapy. ${ }^{42-45}$

\section{The European Journal of Translation Myology Seminal Papers Series}

This mini-review represents an update on the most relevant research on chemotherapy-induced muscle wasting. One of the first studies on this topic was the paper by Damrauer et al. in the Cahcexia 2008 special issue of Basic and Applied Myology (now European Journal of Translation Myology). ${ }^{22}$ Ten years later, this paper was selected for the inaugural issue of the Seminal Papers Series of the European Journal of Translation Myology. ${ }^{21}$ This series provides an opportunity to disseminate to a larger audience seminal papers, previously published in BAM or EJTM, that have paved the way for breakthroughs in translational myology and medicine. The European Journal of Translation Myology has published many papers related to muscle wasting linked to mobility disorders, ${ }^{46-52}$ to muscle atrophy in sarcopenia and disease states, ${ }^{53-55}$ and to physical exercise. ${ }^{33,56}$ EJTM is now entering in all major databases for scientific journals and its impact factor will be released soon. The journal is expanding its authorship, readership, editorial board and enhancing its relevance. Originally devoted to biology, physiology, diagnostic, and the rehabilitation of skeletal muscle tissue, the journal is now moving forward to cover additional fields in myology, thus becoming of a broader medical and clinical interest. We believe that reprinting of specific historical BAM or EJTM papers in the «EJTM Seminal Papers Series» (and publishing of up-dated related reviews) will provide the certain visibility that those papers deserve.

\section{Acknowledgments}

I would like to thank Anna L. Mazzotti for her support in editing this article.

Funding: DC is funded by AFM (2017-20603), ANR (2013-J13R191), EFEM 2016, IBPS (2014), NIH (20131R01CA108857-01subcontractor) and UPMC Emergence (2011-EME1115).

\section{Conflict of Interest}

The author declares no conflicts of interests.

\section{Ethical Publication Statement}

We confirm that we have read the Journal's position on issues involved in ethical publication and affirm that this report is consistent with those guidelines.

\section{Corresponding Author}

Dario Coletti, Institute of Biology Paris-Seine, B2A Biological Adaptation and Ageing, 7 quai St Bernard, bat A, 6eme étage, case courrier 256, 75252 Paris Cedex 5, France. Phone: +33 (0) 1442734 75, fax +33 (0) 144 2721 35, Email: dario.coletti@upmc.fr

\section{References}

1. Baracos VE, Martin L, Korc M, Guttridge DC, Fearon KCH. Cancer-associated cachexia. Nat Rev Dis Primers 2018;4:17105. doi: 10.1038/nrdp.2017.105.

2. Onesti JK, Guttridge DC. Inflammation based regulation of cancer cachexia. Biomed Res Int 2014;2014:168407. doi: 10.1155/2014/168407. Epub 2014 May 4.

3. Pedersen L1, Idorn M2, Olofsson GH2, et al. Voluntary Running Suppresses Tumor Growth through Epinephrine- and IL-6-Dependent NK Cell Mobilization and Redistribution. Cell Metab 2016;23:554-62. doi: 10.1016/j.cmet.2016.01.011. Epub 2016 Feb 16.

4. Flint TR, Janowitz T, Connell CM, et al. TumorInduced IL-6 Reprograms Host Metabolism to Suppress Anti-tumor Immunity. Cell Metab 2016;24:672-684.

doi: 10.1016/j.cmet.2016.10.010.

5. Silvério R, Lira FS, Oyama LM et al. Lipases and lipid droplet-associated protein expression in subcutaneous white adipose tissue of cachectic patients with cancer. Lipids Health Dis 2017;16:159. doi: 10.1186/s12944-017-0547-x.

6. Neves RX, Rosa-Neto JC, Yamashita AS et al. White adipose tissue cells and the progression of cachexia: inflammatory pathways. J Cachexia Sarcopenia Muscle 2016;7:193-203. doi: 10.1002/jcsm.12041. Epub 2015 Jul 7.

7. Berardi E, Aulino P, Murfuni I, et al. Skeletal muscle is enriched in hematopoietic stem cells and not inflammatory cells in cachectic mice. Neurol Res 2008;30:160-9. doi: 10.1179/174313208X281046.

8. Carotenuto F, Coletti D, Di Nardo P, Teodori L. ?Linolenic Acid Reduces TNF-Induced Apoptosis in C2C12 Myoblasts by Regulating Expression of Apoptotic Proteins. Eur J Transl Myol 2016;26:6033. doi: 10.4081/ejtm.2016.6033. eCollection 2016 Sep 15.

9. Moresi V, Garcia-Alvarez G, Pristerà A, et al. Modulation of caspase activity regulates skeletal muscle regeneration and function in response to vasopressin and tumor necrosis factor. PLoS One 2009;4(5):e5570.

doi: 10.1371/journal.pone.0005570. Epub 2009 May 18.

10. Coletti D1, Moresi V, Adamo S, et al. Tumor necrosis factor-alpha gene transfer induces cachexia and inhibits muscle regeneration. Genesis 2005 Nov;43(3):120-8. 


\section{Chemotherapy and muscle wasting}

Eur J Transl Myol 28 (2): 153-157, 2018

11. Tisdale MJ. Molecular pathways leading to cancer cachexia. Physiology (Bethesda) 2005;20:340-8.

12. Barkhudaryan A, Scherbakov N, Springer J, Doehner W. Cardiac muscle wasting in individuals with cancer cachexia. ESC Heart Fail 2017;4:458 467. doi: 10.1002/ehf2.12184. Epub 2017 Jul 15.

13. VanderVeen BN, Hardee JP, Fix DK, Carson JA. Skeletal muscle function during the progression of cancer cachexia in the male ApcMin/+ mouse. J Appl Physiol (1985) 2018;124:684-95. doi: 10.1152/japplphysiol.00897.2017. Epub 2017 Nov 9.

14. Anderson LJ, Liu H, Garcia JM. Sex Differences in Muscle Wasting. Adv Exp Med Biol 2017;1043:153-97. doi: 10.1007/978-3-319-701783_9.

15. Acharyya S1, Guttridge DC. Cancer cachexia signaling pathways continue to emerge yet much still points to the proteasome. Clin Cancer Res 2007;13:1356-61.

16. Salazar-Degracia A, Busquets S, Argilés JM, et al. Formoterol attenuates increased oxidative stress and myosin protein loss in respiratory and limb muscles of cancer cachectic rats. PeerJ 2017;5:e4109. doi: 10.7717/peerj.4109. eCollection 2017.

17. Yoshimura M, Shiomi Y, Ohira Y, et al. Z-505 hydrochloride, an orally active ghrelin agonist, attenuates the progression of cancer cachexia via anabolic hormones in Colon 26 tumor-bearing mice. Eur J Pharmacol 2017;811:30-7. doi: 10.1016/j.ejphar.2017.05.036. Epub 2017 May 18.

18. von Haehling S, Ebner N, Dos Santos MR et al. Muscle wasting and cachexia in heart failure: mechanisms and therapies. Nat Rev Cardiol 2017;14:323-41. doi: 10.1038/nrcardio.2017.51. Epub 2017 Apr 24.

19. Wang J, Bo X, Suo T, et al. Tumor-infiltrating neutrophils predict prognosis and adjuvant chemotherapeutic benefit in patients with biliary cancer. Cancer Sci 2018 May 3. doi: 10.1111/cas.13627.

20. Daly LE, Ní Bhuachalla ÉB, Power DG, et al. Loss of skeletal muscle during systemic chemotherapy is prognostic of poor survival in patients with foregut cancer. J Cachexia Sarcopenia Muscle 2018;9:31525. doi: 10.1002/jcsm.12267. Epub 2018 Jan 9.

21. Damrauer JS, Stadler ME, Acharyya S, et al. Chemotherapy-induced muscle wasting: association with NF-kB and cancer cachexia. Basic Applied Myology 2008;18:139-48. (Reprinted with permission in Eur J Transl Myol 2018;28:158-66).

22. Coletti D. Cachexia as a matter of meat. Basic Applied Myology 2008;18:107-8.

23. Aulino P, Berardi E, Cardillo VM, et al. Molecular, cellular and physiological characterization of the cancer cachexia-inducing C26 colon carcinoma in mouse. BMC Cancer 2010;10:363. doi: 10.1186/1471-2407-10-363.

24. Tilignac $\mathrm{T}$, Temparis $\mathrm{S}$, Combaret $\mathrm{L}$, et al. Chemotherapy inhibits skeletal muscle ubiquitinproteasome-dependent proteolysis. Cancer Res 2002;62:2771-7.

25. Samuels SE, Knowles AL, Tilignac T, et al. Higher skeletal muscle protein synthesis and lower breakdown after chemotherapy in cachectic mice. Am J Physiol Regul Integr Comp Physiol 2001;281:R133-9.

26. Cai D, Frantz JD, Tawa NE Jr, et al. IKKbeta/NFkappaB activation causes severe muscle wasting in mice. Cell 2004;119:285-98.

27. He WA, Berardi E, Cardillo VM, et al. NF-kBmediated Pax7 dysregulation in the muscle microenvironment promotes cancer cachexia. J Clin Invest 2013;123:4821-35.

28. Barreto R, Mandili G, Witzmann FA, et al. Cancer and Chemotherapy Contribute to Muscle Loss by Activating Common Signaling Pathways. Front Physiol 2016;7:472. eCollection 2016.

29. Barreto R, Waning DL, Gao H, et al. Chemotherapy-related cachexia is associated with mitochondrial depletion and the activation of ERK1/2 and p38 MAPKs. Oncotarget 2016;7:43442-60. doi: 10.18632/oncotarget.9779.

30. Liu Q1, Xu WG, Luo Y, et al. Cigarette smokeinduced skeletal muscle atrophy is associated with up-regulation of USP-19 via p38 and ERK MAPKs. J Cell Biochem 2011;112:2307-16. doi: 10.1002/jcb.23151.

31. Barreto R, Kitase $\mathrm{Y}$, Matsumoto $\mathrm{T}$, et al. ACVR2B/Fc counteracts chemotherapy-induced loss of muscle and bone mass. Sci Rep 2017;7:14470. doi: 10.1038/s41598-017-15040-1.

32. Hiroux C, Vandoorne T, Koppo K, et al. Physical Activity Counteracts Tumor Cell Growth in Colon Carcinoma C26-Injected Muscles: An Interim Report. Eur J Transl Myol 2016;26:5958. doi: 10.4081/ejtm.2016.5958. eCollection 2016 Jun 13.

33. Zampieri S, Mosole S, Löfler S, et al. Physical Exercise in Aging: Nine Weeks of Leg Press or Electrical Stimulation Training in 70 Years Old Sedentary Elderly People. Eur J Transl Myol 2015;25:237-42. doi: 10.4081/ejtm.2015.5374. eCollection 2015 Aug 24.

34. Carraro U. From the Padua Muscle Days, the Basic and Applied Myology and the European Journal of Translational Myology to the A\&CM Carraro Foundation for Translational Myology. Eur J Transl Myol 2017;27:7085. doi: 10.4081/ejtm.2017.7085. eCollection 2017 Jun 27.

35. Coletti D, Berardi E, Aulino P, et al. Substrains of inbred mice differ in their physical activity as a behavior. Scientific World Journal 2013;2013:237260. doi: 10.1155/2013/237260. Epub 2013 Mar 6. 


\section{Chemotherapy and muscle wasting}

Eur J Transl Myol 28 (2): 153-157, 2018

36. Pigna E, Berardi E, Aulino P, et al. Aerobic Exercise and Pharmacological Treatments Counteract Cachexia by Modulating Autophagy in Colon Cancer. Sci Rep 2016 May 31;6:26991. doi: 10.1038/srep26991.

37. Coletti D, Aulino P, Pigna E, et al. Spontaneous Physical Activity Downregulates Pax7 in Cancer Cachexia. Stem Cells Int 2016;2016:6729268. doi: 10.1155/2016/6729268. Epub 2015 Dec 20.

38. Barone R, Macaluso F, Sangiorgi C, et al. Skeletal muscle Heat shock protein 60 increases after endurance training and induces peroxisome proliferator-activated receptor gamma coactivator 1 ?1 expression. Sci Rep 2016;6:19781. doi: 10.1038/srep19781.

39. Lira FS, Antunes Bde M, Seelaender M, Rosa Neto JC. The therapeutic potential of exercise to treat cachexia. Curr Opin Support Palliat Care 2015;9:317-24. 10.1097/SPC.0000000000000170.

40. Lira FS, Neto JC, Seelaender M. Exercise training as treatment in cancer cachexia. Appl Physiol Nutr Metab 2014;39:679-86. doi: 10.1139/apnm-20130554. Epub 2014 Mar 24.

41. Maddocks M, Jones LW, Wilcock A. Immunological and hormonal effects of exercise: implications for cancer cachexia. Curr Opin Support Palliat Care 2013;7:376-82. doi: 10.1097/SPC.0000000000000010.

42. Schmidt ME, Wiskemann J, Armbrust P, et al. Effects of resistance exercise on fatigue and quality of life in breast cancer patients undergoing adjuvant chemotherapy: A randomized controlled trial. Int J Cancer 2015;137:471-80. doi: 10.1002/ijc.29383. Epub 2014 Dec 16.

43. Courneya KS, Segal RJ, Mackey JR, et al. Effects of exercise dose and type on sleep quality in breast cancer patients receiving chemotherapy: a multicenter randomized trial. Breast Cancer Res Treat 2014;144:361-9. doi: 10.1007/s10549-0142883-0. Epub 2014 Feb 20.

44. Courneya KS1, Segal RJ, McKenzie DC, et al. Effects of exercise during adjuvant chemotherapy on breast cancer outcomes. Med Sci Sports Exerc 2014;46:1744-51. 10.1249/MSS.0000000000000297.

45. Adamsen L, Quist M, Andersen C, et al. Effect of a multimodal high intensity exercise intervention in cancer patients undergoing chemotherapy: randomised controlled trial. BMJ. 2009;339:b3410. doi: $10.1136 /$ bmj.b3410.

46. Carraro U, Coletti D, Kern H. The Ejtm Specials "The Long-Term Denervated Muscle". Eur J Transl Myol 2014;24:3292. doi: 10.4081/ejtm.2014.3292. eCollection 2014 Mar 31.

47. Sajer S. Mobility disorders and pain, interrelations that need new research concepts and advanced clinical commitments. Eur J Transl Myol
2017;27:7179. doi: 10.4081/ejtm.2017.7179. eCollection 2017 Dec 5.

48. Pette D, Vrbová G. The Contribution of Neuromuscular Stimulation in Elucidating Muscle Plasticity Revisited. Eur J Transl Myol 2017;27(1):6368. doi: 10.4081/ejtm.2017.6368. eCollection 2017 Feb 24.

49. Merico A, Cavinato M1, Gregorio C. Effects of combined endurance and resistance training in Amyotrophic Lateral Sclerosis: A pilot, randomized, controlled study. Eur J Transl Myol 2018;28:7278. doi: 10.4081/ejtm.2018.7278. eCollection 2018 Jan 12.

50. Pigna E, Greco E, Morozzi G, et al. Denervation does not Induce Muscle Atrophy Through Oxidative Stress. Eur J Transl Myol 2017;27:6406. doi: 10.4081/ejtm.2017.6406. eCollection 2017 Feb 24.

51. Mosole S, Carraro U, Kern H, et al. Use it or Lose It: Tonic Activity of Slow Motoneurons Promotes Their Survival and Preferentially Increases Slow Fiber-Type Groupings in Muscles of Old Lifelong Recreational Sportsmen. Eur J Transl Myol 2016;26:5972. doi: 10.4081/ejtm.2016.5972. eCollection 2016 Sep 15.

52. Carraro U, Kern H. Severely Atrophic Human Muscle Fibers With Nuclear Misplacement Survive Many Years of Permanent Denervation. Eur J Transl Myol 2016;26:5894. doi: 10.4081/ejtm.2016.5894. eCollection 2016 Jun 13.

53. Barber L, Scicchitano BM, Musaro A. Molecular and Cellular Mechanisms of Muscle Aging and Sarcopenia and Effects of Electrical Stimulation in Seniors. Eur J Transl Myol 2015;25:231-6. doi: 10.4081/ejtm.2015.5227. eCollection 2015 Aug 24.

54. Hockerman GH, Dethrow NM, Hameed S, et al. The Ubr2 Gene is Expressed in Skeletal Muscle Atrophying as a Result of Hind Limb Suspension, but not Merg1a Expression Alone. Eur J Transl Myol 2014;24:3319. doi: 10.4081/ejtm.2014.3319. eCollection 2014 Sep 23.

55. Costa A, Rossi E, Scicchitano BM, et al. Neurohypophyseal Hormones: Novel Actors of Striated Muscle Development and Homeostasis. Eur J Transl Myol 2014;24:3790. doi: 10.4081/ejtm.2014.3790. eCollection 2014 Sep 23.

56. Coletti D, Adamo S, Moresi V. Of Faeces and Sweat. How Much a Mouse is Willing to Run: Having a Hard Time Measuring Spontaneous Physical Activity in Different Mouse Sub-Strains. Eur J Transl Myol. 2017;27:6483. doi: 10.4081/ejtm.2017.6483. eCollection 2017 Feb 24.

Submission: 04/06/18

Acceptance: 04/06/18 